\title{
Genetic heterogeneity and absence of founder effect in a series of 36 French cerebral cavernous angiomas families
}

\author{
Sophie Laberge ${ }^{1}$, Pierre Labauge ${ }^{1}$, Emmanuelle Maréchal ${ }^{1}$, Jacqueline Maciazek ${ }^{1}$ and \\ Elisabeth Tournier-Lasserve ${ }^{1,2}$
}

${ }^{1}$ INSERM U25. Faculté de Médecine Necker

${ }^{2}$ Hôpital Lariboisière, Paris, France

\begin{abstract}
Cerebral cavernous angiomas malformations (CCM) can be inherited as an autosomal dominant condition. $C C M 1$, a yet unidentified gene mapping on 7q21-q22, was shown to be involved in all CCM Hispano-American families, with a strong founder effect. Genetic heterogeneity in non Hispano-American families was established in two families.

We conducted a genetic linkage analysis on 36 French CCM families using eight microsatellite markers mapping within the CCM1 interval. Admixture analysis showed that $65 \%$ of these families were linked to the CCM1 locus. Haplotypes analysis of CCM1-linked families did not show any evidence for a strong founder effect.
\end{abstract}

Keywords: cavernous angiomas; chromosome 7; founder effect; genetic heterogeneity

\section{Introduction}

Cavernomas are abnormally enlarged capillary cavities without intervening brain parenchyma. Main clinical symptoms include seizures, cerebral haemorrhage, headache and focal neurological deficits. They may occur with an autosomal dominant pattern of inheritance. ${ }^{1}$ In 1995, in a large Hispano-American family, Dubovsky $e t \mathrm{al}^{2}$ mapped a gene, CCM1, to chromosome $7 \mathrm{q}$, within a $33 \mathrm{cM}$ interval. This genetic mapping was further confirmed in a large number of HispanoAmerican families and a strong founder effect was observed in that ethnic group. ${ }^{3-7}$ The size of the genetic interval likely to contain $C C M 1$ was reduced to $4 \mathrm{cM}$, between markers D7S2410 and D7S689. ${ }^{5}$ Only eight

Correspondence: Dr E Tournier-Lasserve, INSERM U25, Faculté de Médecine Necker, 156 Rue de Vaugirard, 75730 Paris Cedex 15, France. Tel: (33) 1456725 97; Fax: (33) 140 5601 07; E-mail: tournier@necker.fr

Received 6 July 1998; revised 11 January 1999; accepted 19 January 1999 non Hispano-American families have been analysed so far. ${ }^{4,5,8-10}$ Two of them were not linked to CCM1, establishing the genetic heterogeneity of this condition. ${ }^{9}$

We report linkage data on 36 French Caucasian CCM families using a panel of eight polymorphic microsatellite markers mapping within the D7S2410-D7S689 interval.

\section{Material and methods}

We selected 36 French families for genotyping (Figure 1). Clinical, neuroimaging features and status criterias were detailed elsewhere. ${ }^{10,11}$ All families were Caucasian and originated from France. A total of 220 potentially informative meioses, including 157 affected individuals, were analysed.

Seven polymorphic microsatellites spanning the CCM1 interval (D7S2410, D7S2409, D7S646, D7S689, D7S1813, D7S1789, D7S558) were chosen from the Généthon linkage map $^{12}$ and from the Cooperative Human Linkage Center. M65B was identified by SL, based on sequencing data of a 

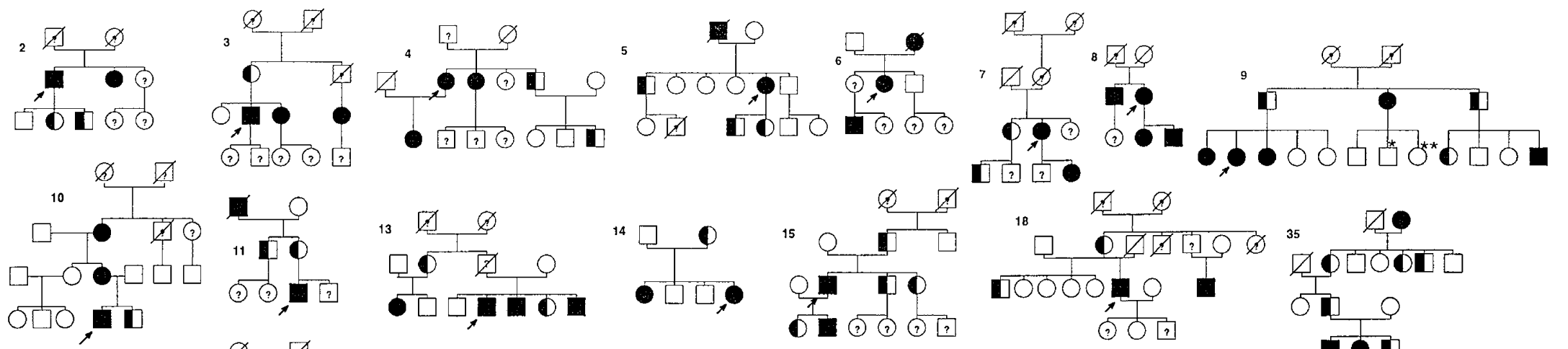

D回回

(1)

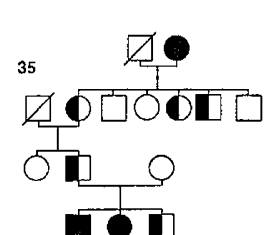

$$
\int_{19}^{\infty}
$$

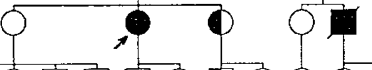

$$
{ }^{20} \varnothing
$$<smiles></smiles>

${ }^{23} \frac{\pi}{\square^{*}}$

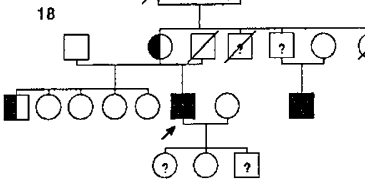

, 01

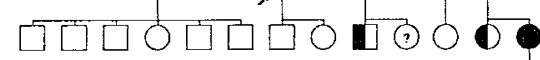

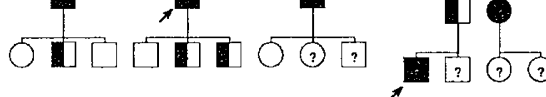

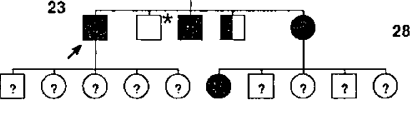

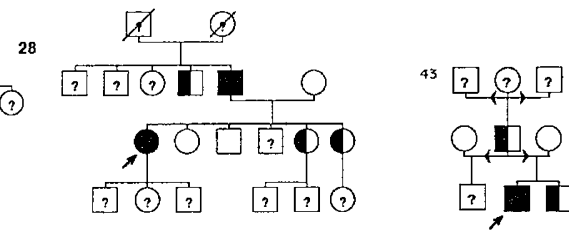
${ }_{27}^{\Delta \phi} \frac{\Delta \phi}{\Delta \varnothing \varnothing}$

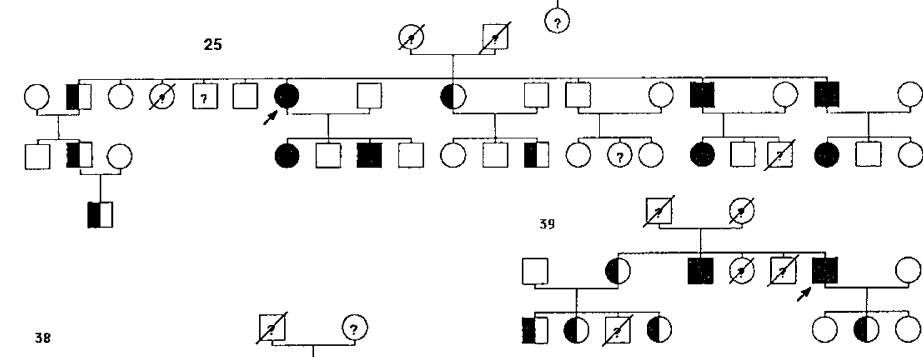

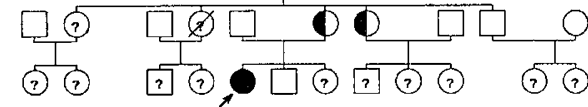

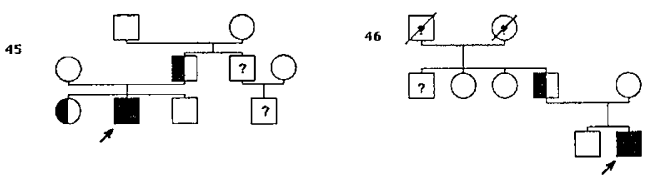

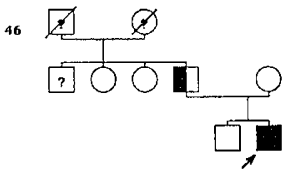

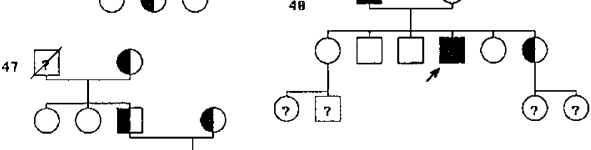

- 0 自回自
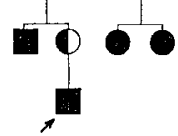

$\square 0$

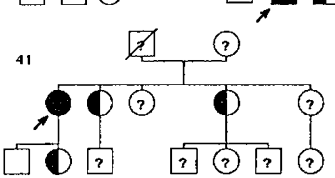

\section{प10}

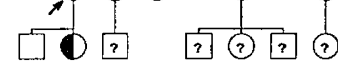
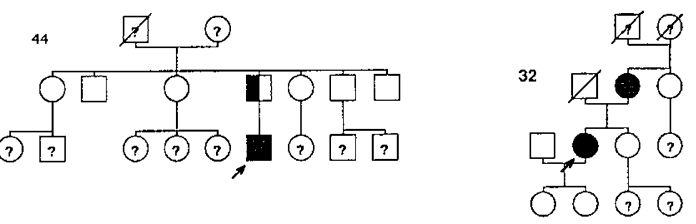

a clinically afrected 1 Asymptomatic, IRM
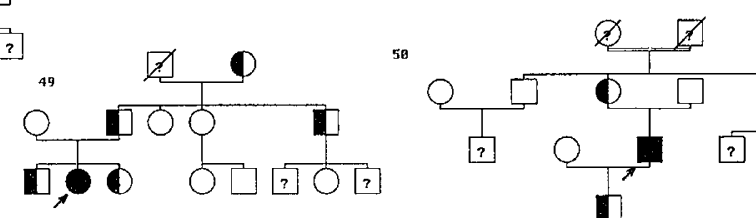

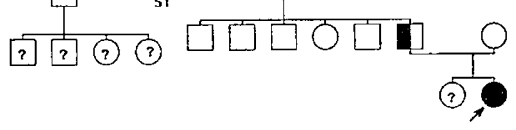

\footnotetext{
$\bigcap$ Healthu Individuals
}

ก. Unknown

Figure 1 Pedigrees of the 36 CCM families. Solid symbols: symptomatic CCM patients having cavernous angiomas on cerebral MRI; half filled symbols: asymptomatic individuals having cavernomas on MRI; open symbols: asymptomatic individuals having a normal MRI; ?:members of unknown status. * = recombinant individual in families F9, F23. An additional recombinant event occurred in F27 (see text) 
bacterial artificial chromosome (RG085C05) mapped within the D7S2410-D7S689 interval.

Linkage analysis was performed as previously described. ${ }^{10}$ Parameters for linkage analysis were based on a combination of epidemiological ${ }^{13}$ and clinical/Magnetic Resonnance Imaging (MRI) data from the French CCM families. ${ }^{11}$ Briefly, large autopsies and MRI series estimated the prevalence of cavernous angiomas in the general population to be close to $0.5-1 \% .^{13}$ In the French population, $10-20 \%$ of these cavernous angiomas are hereditary (ETL, unpublished results). The penetrance was estimated to be close to $90 \%$ when MRI was used to establish the status. ${ }^{11}$ Therefore linkage parameters were established as follows: phenocopy prevalence of 0.01 , gene frequency of 0.001 and $90 \%$ penetrance.

Multilocus analysis of the four most informative markers (D7S2410, M65B, D7S646 and D7S689) was computed after recoding each marker to a three alleles system which did not change significantly the results of the two-point analysis for any of the latter markers. Genetic linkage analysis of a subset of CEPH families and of our families, as well as physical mapping data, ${ }^{12}$ (SL, unpublished results) strongly suggest that the most likely order of markers used for multipoint linkage analysis is D7S2410-(0.03)-M65B(0.005)-D7S646-(0.005)-D7S689. Homogeneity was assessed using the admixture test implemented in the HOMOG program package.

\section{Results}

Significant lod scores were obtained for family 25 with several markers (Table 1$)$. Lod scores higher than 1 were obtained in eight additional families (families $3,9,10,13,23,27,35,40)$ with at least two markers. Negative lod scores values $<-2$ were obtained for four families (families 2, 20, 39, 49).

HOMOG admixture analyses of multipoint data are shown in Table 2. The percentage of families linked to $C C M 1$ was estimated to be close to $65 \%$. Nine families displayed a conditional probability $P P$ to be linked to the $C C M 1$ locus above 0.95 and four families had a $P P<0.1 \%$.

Analysis of the CCM1 haplotypes of the nine families having a conditional probability to be linked $>95 \%$ showed that none of these families shared the HispanoAmerican haplotype (Figure 2). Some alleles such as $M 65 B-133 b$ p were frequent but there was no significant difference of frequency when compared with our control population (spouses and unlinked haplotypes) using the $p$-excess methodology. ${ }^{6}$ Comparative analysis of the nine linked haplotypes (Figure 2) did not show evidence for a founder effect.

Four recombinant events were observed within the nine linked families. Three of them were observed in healthy individuals having a normal MRI and aged 35 and 33 years old (F9*, F9**) and 56 years old (F23*).
Table 2 HOMOG analysis of multipoint data

\begin{tabular}{|c|c|c|c|c|c|c|}
\hline Families & $A^{a}$ & $H^{a}$ & $U^{a}$ & $\begin{array}{l}\text { Cond } \\
\text { prob }\end{array}$ & $\begin{array}{l}\text { lower } \\
\text { limit }\end{array}$ & $\begin{array}{l}\text { upper } \\
\text { limit }\end{array}$ \\
\hline 3 & 4 & 1 & 0 & 0.96 & 0.88 & 0.99 \\
\hline 9 & 8 & 7 & 1 & 0.99 & 0.98 & 1.00 \\
\hline 10 & 4 & 6 & 0 & 0.96 & 0.89 & 0.99 \\
\hline 13 & 6 & 2 & 0 & 0.99 & 0.94 & 1.00 \\
\hline 19 & 5 & 10 & 0 & 0.99 & 0.99 & 1.00 \\
\hline 23 & 4 & 1 & 1 & 0.97 & 0.86 & 0.99 \\
\hline 25 & 12 & 12 & 1 & 1.00 & 1.00 & 1.00 \\
\hline 27 & 8 & 1 & 0 & 0.99 & 0.96 & 1.00 \\
\hline 40 & 3 & 4 & 0 & 0.98 & 0.94 & 0.99 \\
\hline 4 & 5 & 1 & 0 & 0.26 & 0.01 & 0.62 \\
\hline 5 & 4 & 7 & 0 & 0.81 & 0.29 & 0.95 \\
\hline 6 & 1 & 2 & 2 & 0.77 & 0.54 & 0.92 \\
\hline 7 & 4 & 0 & 1 & 0.88 & 0.71 & 0.96 \\
\hline 8 & 4 & 0 & 0 & 0.87 & 0.69 & 0.96 \\
\hline 11 & 3 & 0 & 0 & 0.78 & 0.55 & 0.92 \\
\hline 14 & 3 & 2 & 0 & 0.58 & 0.32 & 0.82 \\
\hline 15 & 5 & 1 & 0 & 0.80 & 0.58 & 0.93 \\
\hline 18 & 3 & 4 & 3 & 0.88 & 0.72 & 0.96 \\
\hline 21 & 3 & 0 & 0 & 0.78 & 0.55 & 0.92 \\
\hline 28 & 5 & 5 & 0 & 0.89 & 0.74 & 0.97 \\
\hline 32 & 2 & 2 & 0 & 0.85 & 0.67 & 0.95 \\
\hline 35 & 8 & 4 & 0 & 0.90 & 0.75 & 0.97 \\
\hline 38 & 3 & 0 & 2 & 0.77 & 0.53 & 0.92 \\
\hline 41 & 4 & 1 & 1 & 0.92 & 0.81 & 0.98 \\
\hline 42 & 4 & 0 & 0 & 0.91 & 0.77 & 0.97 \\
\hline 43 & 3 & 1 & 0 & 0.83 & 0.62 & 0.94 \\
\hline 44 & 2 & 6 & 0 & 0.04 & 0.01 & 0.14 \\
\hline 45 & 3 & 2 & 0 & 0.40 & 0.19 & 0.69 \\
\hline 46 & 2 & 3 & 0 & 0.12 & 0.04 & 0.33 \\
\hline 47 & 4 & 2 & 0 & 0.14 & 0.04 & 0.37 \\
\hline 50 & 3 & 2 & 0 & 0.44 & 0.21 & 0.73 \\
\hline 51 & 2 & 5 & 0 & 0.27 & 0.11 & 0.55 \\
\hline 2 & 4 & 1 & 0 & 0.01 & 0.00 & 0.02 \\
\hline 20 & 6 & 4 & 0 & 0.01 & 0.00 & 0.04 \\
\hline 39 & 7 & 2 & 0 & 0.00 & 0.00 & 0.00 \\
\hline 49 & 6 & 5 & 0 & 0.00 & 0.00 & 0.01 \\
\hline $\mathrm{H} 2$ & & & & $\mathrm{Zmax}=9.12$ & $\alpha=0.65$ & $\theta=0.017$ \\
\hline$\overline{\mathrm{H} 1}$ & & & & $\mathrm{Zmax}=3.93$ & $\alpha=1.00$ & $\theta=0.012$ \\
\hline
\end{tabular}

${ }^{a}$ Number of individuals sampled: $\mathrm{A}=$ Affected, $\mathrm{H}=$ Healthy and $\mathrm{U}=$ Unknown status.

*HOMOG data obtained under the hypotheses of Heterogeneity (H2) and Homogeneity (H1).

$\mathrm{F}^{*}$ was recombinant at $\mathrm{D} 7 \mathrm{~S} 2410$ and carried the 'healthy' alleles for the other markers. F9** carried the whole affected haplotype due either to a double recombination event within the CCM1 interval or to the incomplete penetrance of this condition. F23* was recombinant with $\mathrm{D} 7 \mathrm{~S} 2410$ and was no more recombinant with telomeric markers. In family F27, a recombination event also occurred with marker D7S2410 within an affected individual: affected individuals belonging to two of the three branches of this family did not share any allele for this marker. No other recombination event was detectable in this family. 
Société Française de Neurochirurgie. SL and PL have contributed equally to the study.

\section{References}

1 Rigamonti D, Hadley MN, Drayer BP et al: Cerebral cavernous malformations. Incidence and familial occurrence. $N$ Engl J Med 1988; 319: 343-347.

2 Dubovsky J, Zabramski JM, Kurth J et al: A gene responsible for cavernous malformations of the brain maps to chromosome 7. Hum Mol Genet 1995; 4: 453-458.

3 Günel M, Awad IA, Anson J, Lifton RP: Mapping a gene causing cerebral cavernous malformation to 7q11.2 q21. Proc Natl Acad Sci USA 1995; 92: 6620-6624.

4 Marchuk DA, Gallione CJ, Morrison LA et al: A locus for cerebral cavernous malformations maps to chromosome 7q in two families. Genomics 1995; 28: 311-314.

5 Johnson EW, Lyer LM, Rich SS et al: Refined localization of the cerebral cavernous malformation gene CCM1 to a 4-cM interval of chromosome $7 \mathrm{q}$ contained in a welldefined YAC Contig. Genome Res 1995; 5: 368-380.

6 Günel M, Awad IA, Finberg K et al: A founder mutation as a cause of cerebral cavernous malformation in Hispanic Americans. N Engl J Med 1996a; 334: 946-951.

7 Polymeropoulos MH, Hurko O, Hsu F et al: Linkage of the locus for cerebral cavernous hemangiomas to human chromosome $7 \mathrm{q}$ in four families of Mexican-American descent. Neurology 1997; 48: 752-757.

8 Gil-Nagel A, Dubovsky J, Wilcox KJ et al: Familial cerebral cavernous angioma: a gene localized to a $15 \mathrm{cM}$ interval on chromosome 7q. Ann Neurol 1996; 39: 807-810.

9 Günel M, Awad IA, Finberg K et al: Genetic heterogeneity of inherited cerebral cavernous malformation. Neurosurgery $1996 \mathrm{~b} ; 38$ : $1265-1271$.

10 Notelet L, Chapon F, Khoury S et al: Familial cavernous malformations in a large French kindred: mapping of the gene to the CCM1 locus on chromosome 7q. J Neurol Neurosurg Psychiatry 1997; 63: 40-45.

11 Labauge P, Laberge S, Brunereau L et al: Hereditary cerebral cavernous angiomas: clinical and genetic features in 57 French families. Lancet 1998; 352: 1892-1897.

12 Dib C, Fauré S, Fizames C, Samson D et al: A comprehensive genetic map of the human genome based on 5,264 microsatellites. Nature 1996; 380: A54-A55.

13 Otten P, Pizzolato GP, Rilliet B, Berney J: A propos de 131 cas d'angiomes caverneux (cavernomes) du SNC, repérés par l'analyse rétrospective de 24535 autopsies. Neurochirurgie 1989; 35: 82-83. 